\title{
Head and neck myxofibrosarcoma: a case report and review of the literature
}

\author{
Giovanni Dell'Aversana Orabona', Giorgio laconetta ${ }^{2}$, Vincenzo Abbate ${ }^{1,3^{*}}$, Pasquale Piombino ${ }^{1}$, Antonio Romano ${ }^{1}$ \\ Fabio Maglitto ${ }^{1}$, Giovanni Salzano ${ }^{1}$ and Luigi Califano ${ }^{1}$
}

\begin{abstract}
Introduction: Myxofibrosarcoma is the most common soft tissue sarcoma that occurs in late adult life, peaking in the seventh decade, and it is mainly encountered in the lower extremities. Myxofibrosarcoma of the head and neck are extremely rare. To the best of our knowledge, only 19 cases have been described in the head and neck so far. This is a literature review and retrospective chart review of our experience in head and neck myxofibrosarcoma treatment in our department.
\end{abstract}

Case presentation: In this case report we describe a 35-year-old Caucasian man who presented the first case of myxofibrosarcoma arising from the pterygopalatine fossa. The peculiar anatomical location and the extent in the midcheek region make this case a hard "challenge" for the surgeon, in order to guarantee wide surgical margins of resection. A total right maxillectomy was accomplished by means of the Weber-Ferguson approach, preserving the orbital floor. The excised portion was reconstructed using the free rectus abdominis myocutaneous flap. Postoperative radiotherapy was given to the area adjacent to the lesion, with a total dose of 60Gy. No relapse occurred in the 27-month postoperative follow-up.

Conclusions: The case described suggests the importance of combined surgical and adjuvant radiotherapy to avoid local and distant recurrences of the tumor. In our opinion, combined surgical and adjuvant radiotherapy followed by close clinical observation to search for a metastatic disease is advisable in all cases. Further studies are needed to confirm the efficacy of combined radio-chemotherapy for head and neck myxofibrosarcoma in terms of long-term disease-free survival.

Keywords: Malignant fibrous histiocytoma, Midcheek masses, Myxofibrosarcoma, Myxosarcoma

\section{Introduction}

The terms "myxofibrosarcoma" (MFS) and "myxosarcoma" refer to a connective tissue neoplasm of fibroblastic origin set in myxoid matrix which has been classified by O'Brien and Stout [1] as a myxoid variant of malignant fibrous histiocytoma (MFH) [2,3]. In 2002, the World Health Organization [4] declassified the MFH as a diagnostic entity and determined that myxoid MFH without myogenic, lipoblastic and chondrogenic features be diagnosed as MFS. MFS is the most common soft tissue sarcoma

\footnotetext{
* Correspondence: abbate.maxfacc@gmail.com

'Department of Maxillofacial surgery, University of Naples "Federico II", Naples, Italy

${ }^{3}$ MaxilloFacial Surgery Unit, Department of Neurosciences and Reproductive and Odontostomatological Sciences, Federico II University of Naples, Via Pansini, 5, 80131 Naples, Italy

Full list of author information is available at the end of the article
}

that occurs in late adult life, peaking in the seventh decade and is mainly encountered in the lower extremities (77\%), trunk (12\%), retroperitoneum or mediastinum (8\%). Only a few corresponding cases in the head and neck region have been reported to date, with 3 to $10 \%$ involvement. This is a literature review and retrospective chart review of our experience in head and neck MFS treatment in our department. The purpose of this study is to provide the reader with an overview of the pathology of this complex anatomic area focusing attention on the differential diagnosis and recent treatment strategies. Furthermore we describe the first case of MFS arising from the pterygopalatine fossa extending to the soft tissues of the midcheek area. We discuss the clinical, histological, immunohistochemical and ultrastructural features of these large neoplasms in such a rare and critical anatomical area. 


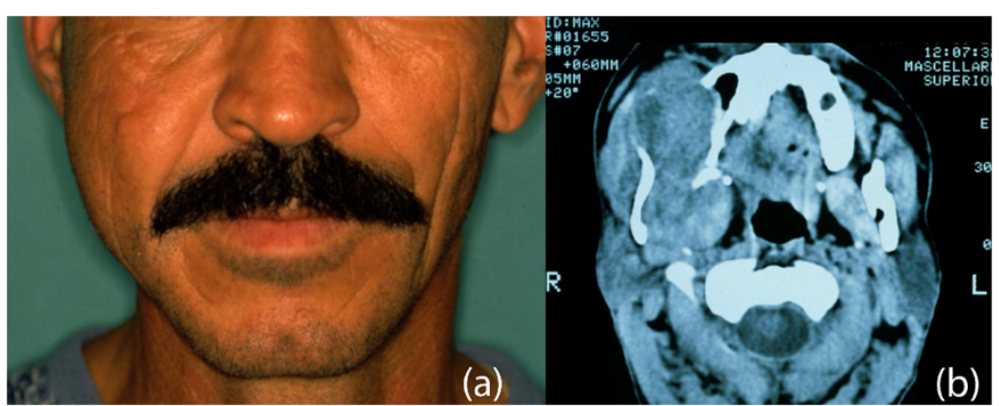

Figure 1 Preoperative patient's study. (a) Patient's facial appearance. (b) Axial computed tomography scan showing the extent of the tumor.

\section{Case presentation}

A 35-year-old Caucasian man presented with a complaint of facial asymmetry for a mass in his right midcheek area, which had increased in size over 4 months (Figure 1a). In January 2011, he was admitted to our Department of Maxillofacial Surgery complaining of right cheek discomfort and pain, refractory to analgesics, in his right maxilla area and radiating to the right zygoma. Two weeks before the onset of pain, he underwent an examination by his dentist. When he came to our observation, an apparent swelling of the right side of his face was observed, with anesthesia, in the area of his face innervated by the second branch of the trigeminal nerve, and he had pain on palpation. An intraoral examination revealed an expansion of his upper right gums and the vestibular portion, and the mucosa appeared reddened, and his teeth were movable with the presence of a widespread periodontitis. No lymphadenopathy was apparent at neck examination. Computed tomography revealed a hyperdense mass lesion, measuring $83 \times 55 \mathrm{~mm}$ in its greatest dimension, arising from the pterygopalatine fossa, and extending to the soft tissue of his midcheek area (Figure 1b). An open biopsy was conducted for the diagnosis. The biopsy specimen was histologically examined; it was found to be composed of fibroma and exhibited myxomatous changes as well as abundant collagen fibers. The tumor was characterized by spindle-cell proliferation with moderate cellular density in the fibromyxoid stroma. On immunohistochemical examination, the tumor cells were positive for vimentin, Ki-67, smooth muscle actin, but negative for S-100 (Figure 2a,b).

A total right maxillectomy was accomplished by means of Weber-Ferguson approach, preserving the orbital floor. On macroscopic examination the anterior and the

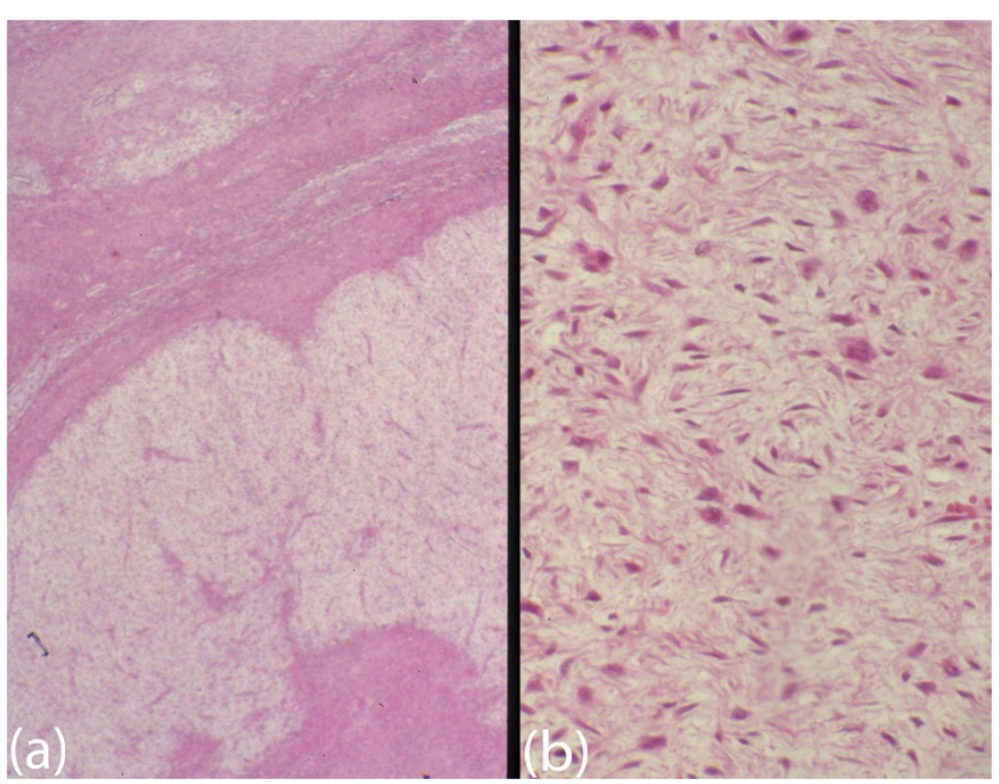

Figure 2 Histological appearance. (a) Photomicrograph showing myxoid nodules and fibrous septa. Hematoxylin and eosin original magnification $\times 40$. (b) Photomicrograph showing spindle-shaped cells in a fascicular arrangement. Hematoxylin and eosin, original magnification $\times 100$. 
posterior maxillary walls were totally reabsorbed and the tumor was removed from the pterygopalatine fossa (Figure 3). In the right midcheek area, the tumor was detached from the subcutaneous tissues with safe margins preserving the skin. The excised portion was reconstructed using the free rectus abdominis myocutaneous flap. The size of the excised tumor was approximately $84 \times 56 \times 58 \mathrm{~mm}$; it was well circumscribed, elastic, and homogeneously whitish in color. The final diagnosis was low-grade MFS. Postoperative radiotherapy was given to the area adjacent to the lesion, with a total dose of 60Gy. No relapse occurred in 27-month postoperative follow-up.

\section{Discussion}

MFS of the head and of the neck are extremely rare. To the best of our knowledge, only 19 cases have been previously described in the head and neck so far (Table 1), our case being the first observed within the pterygopalatine fossa. Apart from the general histologic features, MFS demonstrates wide histologic variability, based on its grade of malignancy. These tumors have been subdivided into three or four grades based on the degree of cellularity, nuclear pleomorphism, and mitotic activity $[5,6]$. Low-grade MFSs are considered to have low malignancy, and rarely show distant metastasis, implying a good short-term prognosis. Mentzel et al. [5], in their study, reviewed 75 patients and documented local recurrence in $55 \%$ of cases and distant metastases in 33\%. More recently, Nishio et al. [7] reported an overall 5year survival rate of 60 to $70 \%$; however, the local recurrence rate of the low-grade type is as high (50\% to 60\%) as that of the high-grade type. Sanfilippo et al. [8], in a review of 178 patients, stated that, while local recurrences were predicted by the quality of surgical margins, the distant metastases were observed based on histological grade. Zhu Qiubei et al. [9] reviewed, from 1981 until 2012, 18 cases. The average age of onset reported was 53 years with male prevalence (66.7\%). The average

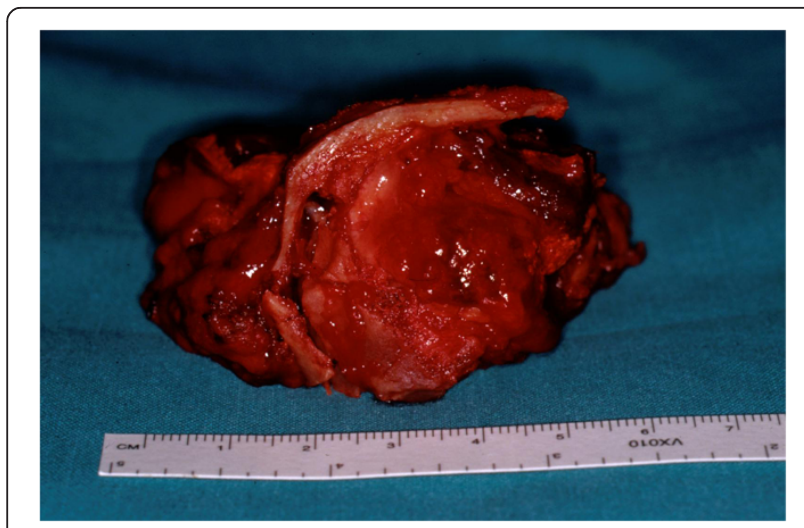

Figure 3 Overall view of the tumor.
Table 1 Cases of myxofibrosarcoma in the head and neck region

\begin{tabular}{lc}
\hline Region & Cases \\
\hline Maxillary sinus & 3 \\
Sphenoid sinus & 3 \\
Orbit & 2 \\
Maxilla & 2 \\
Esophagus & 1 \\
Hypopharynx & 1 \\
Neck & 1 \\
Vocal folds & 1 \\
Parotid & 3 \\
Mandible & 1 \\
Infratemporal space & 1 \\
Total of cases reported in head and neck & $\mathbf{1 9}$ \\
\hline
\end{tabular}

follow-up after treatment for all the cases of MSF of head and neck described was 17 months (range 3 to 39 months). None of the patients reported developed locoregional lymph node or systemic metastases at the latest follow-up. Surgery followed by adjuvant radiotherapy was the most common form of treatment strategy, and only two articles dealing with radio/chemotherapy exist, due to the small number of cases. Cante et al. [10] reported one case of MSF of maxillary sinus with a

Table 2 Head and neck myxofibrosarcoma: review of cases

\begin{tabular}{lcll}
\hline Sex & Age (years) & Treatment & Follow-up \\
\hline Male & 66 & Radiotherapy & 3 months \\
Male & 58 & Surgery & Unknown \\
Female & 67 & Surgery, radiotherapy & 8 months \\
Female & 52 & Surgery & Unknown \\
Male & 55 & Surgery & 8 months \\
Male & Unknown & Unknown & Unknown \\
Male & 40 & Surgery & Unknown \\
Male & 69 & Surgery & 16 months \\
Male & 55 & Surgery & 27 months \\
Female & 36 & Surgery & 24 months \\
Male & 79 & Surgery & Unknown \\
Female & 37 & Surgery, radiotherapy & 8 months \\
Female & 27 & Surgery, radiotherapy & 6 months \\
Male & 23 & Surgery, radiotherapy & 39 months \\
Male & 69 & Radiotherapy, chemotherapy & 12 months \\
Female & 78 & Surgery, radiotherapy & 24 months \\
Female & 42 & Surgery, radiotherapy & 26 months \\
Male & 52 & Surgery, radiotherapy & 20 months \\
Male & 65 & Radiotherapy, chemotherapy & 18 months \\
\hline
\end{tabular}


complete remission at 18-month follow-up after a combined radio-chemotherapy (RT/CHT) without surgery (Table 2). The results obtained with combined RT/CHT treatment for head and neck MFS should encourage further studies to confirm the efficacy in terms of long-term disease-free survival. According to these considerations, a complete tumor resection with adequate resection margins, followed by adjuvant radiotherapy, remains the mainstay for treatment of MFS. A possible re-excision of recurrent lesions is considered the mainstay of therapy for disease control.

\section{Conclusions}

In conclusion, the peculiar anatomical location and the extent in midcheek region, make such a case a hard "challenge" for the surgeon in order to guarantee wide surgical margins of resection. Combined surgical and adjuvant radiotherapy, in order to avoid local and distant recurrences of the tumor, is absolutely recommended. An aggressive follow-up in order to search for a metastatic disease is advisable in all cases. Further studies are needed to confirm the efficacy of combined RT/CHT for head and neck MSF in terms of long-term disease-free survival.

\section{Consent}

Written informed consent was obtained from the patient for publication of this case report and accompanying images. A copy of the written consent is available for review by the Editor-in-Chief of this journal.

\footnotetext{
Abbreviations

MFH: Malignant fibrous histiocytoma; MFS: Myxofibrosarcoma; RT/CHT: Combined radio-chemotherapy.
}

\section{Competing interests}

The authors declare that they have no competing interests.

\section{Authors' contributions}

GDO was the major contributor in writing the manuscript. FM reviewed the manuscript. VA and PP were responsible for the clinical management of the patient; LC and Gl performed the surgery procedure. All authors read and approved the final manuscript.

\section{Acknowledgments}

The authors are greatly indebted to and thankful for Alfonso Manfuso MD, University of Naples "Federico II", Naples, Italy for unstinting efforts and utter devotion in the development of this article.

\section{Author details}

'Department of Maxillofacial surgery, University of Naples "Federico II", Naples, Italy. ${ }^{2}$ Department of Neurosurgery, University of Salerno, Salerno, Italy. ${ }^{3}$ MaxilloFacial Surgery Unit, Department of Neurosciences and Reproductive and Odontostomatological Sciences, Federico II University of Naples, Via Pansini, 5, 80131 Naples, Italy.

Received: 16 July 2014 Accepted: 4 December 2014 Published: 29 December 2014

\section{References}

1. O'Brien JE, Stout AP: Malignant fibrous xanthomas. Cancer 1964, 17:1445-1455.
2. Mansoor A, White CR Jr: Myxofibrosarcoma presenting in the skin: clinicopathological features and differential diagnosis with cutaneous myxoid neoplasms. Am J Dermatopathol 2003, 25(4):281-286. PubMed PMID: 12876484.

3. Wada T, Hasegawa T, Nagoya S, Kawaguchi S, Kaya M, Ishii S: Myxofibrosarcoma with an infiltrative growth pattern: a case report. Jpn J Clin Oncol 2000, 30(10):458-462. PubMed PMID: 11185894.

4. Fletcher CDM, Mehrtens F: World Health Organization Classification of Tumors: Pathology and Genetics of Tumors of Soft Tissue and Bone. France: IARC Press; 2002.

5. Mentzel T, Calonje E, Wadden C, Camplejohn RS, Beham A, Smith MA, Fletcher CD: Myxofibrosarcoma. Clinicopathologic analysis of 75 cases with emphasis on the low-grade variant. Am J Surg Pathol 1996, 20(4):391-405. PubMed PMID: 8604805. 6.

6. Huang HY, Lal P, Qin J, Brennan MF, Antonescu CR: Low-grade myxofibrosarcoma: a clinicopathologic analysis of 49 cases treated at a single institution with simultaneous assessment of the efficacy of 3-tier and 4-tier grading systems. Hum Pathol 2004, 35(5):612-621. PubMed PMID: 15138937.

7. Nishio J, Iwasaki H, Nabeshima K, Naito M: Cytogenetics and molecular genetics of myxoid soft-tissue sarcomas. Genet Res Int 2011, 2011:497148. doi:10.4061/2011/497148. Epub 2011 Jul 28; PubMed PMID: 22567356; PubMed Central PMCID: PMC3335514.

8. Sanfilippo R, Miceli R, Grosso F, Fiore M, Puma E, Pennacchioli E, Barisella M, Sangalli C, Mariani L, Casali PG, Gronchi A: Myxofibrosarcoma: prognostic factors and survival in a series of patients treated at a single institution Ann Surg Oncol 2011, 18(3):720-725. doi:10.1245/s10434-010-1341-4. Epub 2010 Sep 28. PubMed PMID: 20878245.

9. Qiubei Z, Cheng L, Yaping X, Shunzhang L, Jingping F: Myxofibrosarcoma of the sinus piriformis: case report and literature review. World J Surg Oncol 2012, 10:245. doi:10.1186/1477-7819-10-245. Review. PubMed PMID: 23152982. PubMed Central PMCID: PMC3534627.

10. Cante D, Franco P, Sciacero P, Girelli GF, Casanova Borca V, Pasquino M, Tofani S, Bombaci S, Migliaccio F, Marra A, Numico G, La Porta MR, Ricardi U: Combined chemoradiation for head and neck region myxofibrosarcoma of the maxillary sinus. Tumori 2013, 99(2):e80-e83. doi:10.1700/1283.14214. PubMed PMID: 23748836.

doi:10.1186/1752-1947-8-468

Cite this article as: Dell'Aversana Orabona et al: Head and neck myxofibrosarcoma: a case report and review of the literature. Journal of Medical Case Reports 2014 8:468.

\section{Submit your next manuscript to BioMed Central and take full advantage of:}

- Convenient online submission

- Thorough peer review

- No space constraints or color figure charges

- Immediate publication on acceptance

- Inclusion in PubMed, CAS, Scopus and Google Scholar

- Research which is freely available for redistribution 